\title{
Market Structure, Efficiency, and Performance of Jordan Insurance Market
}

\author{
Mutasem Jaloudi ${ }^{1, ~ *, ~ A m i r ~ B a k i r ~}{ }^{2}$ \\ ${ }^{1}$ Insurance Directorate, Ministry of Industry, Trade, and Supply, Amman, Jordan \\ ${ }^{2}$ Department of Business Economics, School of Business, University of Jordan, Amman, Jordan
}

Email address:

m_jdi@hotmail.com (M. Jaloudi)

${ }^{*}$ Corresponding author

\section{To cite this article:}

Mutasem Jaloudi, Amir Bakir. Market Structure, Efficiency, and Performance of Jordan Insurance Market. International Journal of Business and Economics Research. Vol. 8, No. 1, 2019, pp. 6-13. doi: 10.11648/j.ijber.20190801.12

Received: December 19, 2018; Accepted: January 10, 2019; Published: January 28, 2019

\begin{abstract}
This study aims to investigate the impact of the market share, according to the SCP hypothesis, technical efficiency, according to the ES hypothesis, and other control variables on the performance of insurance companies in Jordan. The study used panel data for 22 insurance companies operating in Jordan during 2000-2016. The authors used the HerfindahlHirschman Index (HHI) and the concentration ratio (CR) to evaluate the Market structure of the insurance sector, Also employed market share as a proxy of the SCP hypothesis while efficiency score estimated using the DEA technique to proxy for the ES hypothesis, control variables were (Reinsurance, leverage, and Underwriting risk), while the dependent variable, performance was measured as return on assets. The model estimated using Random Effect GLS. The study found that the insurance market in Jordan is highly concentrated, where a few insurers control a large market share of premiums. Also, the result supports the (SCP) hypothesis for the insurance market in Jordan, and Reinsurance, leverage, and Underwriting Risk have a negative relationship with ROA. This is the first study -to the best author's knowledge - to test SCP and ES hypothesis in the insurance sector in Jordan.
\end{abstract}

Keywords: Insurance, DEA, Structure-Conduct-Performance, Efficient Structure, Performance, Jordan

\section{Introduction}

The literature on the competitive conditions of financial institutions suggests the use of two approaches: structural approach and non-structural approach. The structural approach highlights the nature of competition in the industry from structural characteristics such as concentration, number of companies and market share [1]. This Approach uses two main hypotheses to explain the positive relationship between market concentration or market share with profitability: StructureConduct-Performance (SCP) and Efficient Structure (ES).

In 1999, a new insurance law was issued in Jordan in accordance with international standards in order to develop and regulate the insurance market in Jordan. During the period 2000-2016, changes took place in the structure of the insurance market in Jordan, whether in the entry of new companies and the occurrence of mergers or exit and liquidation of existing companies.

The insurance market in Jordan is currently composed of
(24) insurance companies. Whereof one is licensed as a life company, (9) are non-life companies, and (14) are composite companies. At 2016, Gross written premiums in Jordan reached JOD (582.9) million, and the gross Claims paid reached JOD (438.9) million. In the same year, the sector earned JOD (35.1) million in net profits before, the return on assets was $(3.8 \%)$, and the return on equity was $(10.2 \%)$.

The insurance sector in Jordan faces many challenges that require our attention; hence, there is a vital need to find solutions to these challenges. These challenges include the existence of a large number of insurance companies in relative to the size of the market, low per capita income, low solvency of insurance companies, additionally, the insurance sector was affected by the global financial crises and the repercussions of regional political troubles [2].

Despite these challenges, the relative importance of the insurance sector in Jordan increased during the period (20002016), where gross written premiums increased at an annual rate of $(12 \%)$, insurance premiums per capita increased by 
(187\%), which increased from JOD (21) to JOD (59) at that period. In addition, the ratio of gross premiums to the gross domestic product (insurance penetration ratio) increased from $(1.7 \%)$ in 2000 to $(2.1 \%)$ in 2016.

Despite the increase of research on the relationship between concentration and profitability in many industries, the existence of such a relationship in the insurance sector of Jordan has not received much attention in the literature. The purpose of this study is to fill the gap in existing literature by investigating the effect of market share as a proxy of the SCP hypothesis and the efficiency using the DEA technique to proxy for the ES hypothesis, in addition to other factors that appear to effect on the performance of insurance companies in Jordan.

The importance of this study comes from the fact that it provides insurance management with relevant indicators about the factor that affect their company's performance. In addition, this is the first study -to the best author's knowledge - to test SCP and ES hypothesis in the insurance sector in Jordan, besides that it covers the period following the adoption of the Insurance Law and the issuance of most of the legislation related to the insurance company's business.

This study will be organized as follows: In addition to this section one, the introduction, section two review the literature and empirical studies. This is followed by section three, which describe the data and methodology. The fourth section discusses and analyses the data. The paper concludes with a brief summary, conclusion, and recommendations.

\section{Literature Review and Empirical Studies}

The framework of the Structure-Conduct-Performance (SCP) derived from the neoclassical analysis of the market; this model developed by Mason [3] and Bain [1]. The (SCP) assumes that the market structure, with characteristics such as the number of companies, its market shares, entry and exit barriers and the elasticity of price demand, influences business behavior, and determines the behavior of companies directly or indirectly, whether they are in competition or collusion, to make their decisions regarding pricing, advertising, research and development, in a way that affects their performance in the market, which is expressed by profitability and market growth.

The (SCP) asserts that companies operating in markets with concentrated nature can gain monopoly profits as a result of incomplete competition and thus the performance of the industry depends on the behavior of sellers and buyers, which depends on the structure of the industry. The assumption is that the decline in the number of firms in the market may lead to a firm collusion [4]. The collusion between companies increases in a concentrated industry because concentration reduces the cost of the collusion. Prices - a factor that is less favorable to consumers positively impact firm performance, such as profitability, that is, the company's concentration provides conditions for anticompetitive behavior that leads to monopolistic profits [5].
The inverse relationship between the degree of concentration and the degree of competition was the basic assumption of (SCP) because market concentration encourages firms to collude. This model indicates that there is a direct relation between the degree of market concentration and the degree of competition among firms. This hypothesis supports the notion that there is a positive relationship between market concentration (measured by concentration ratio) and performance (measured by profit) regardless of the efficiency. Therefore, companies that are more concentrated will earn more profits than companies in less concentrated industries, regardless of their efficiency [6].

The efficient structure hypothesis (ES) suggests that efficiency is what explains the positive relationship between market concentration and profitability. Efficient companies are growing in size and market share due to their ability to make greater profits. According to (ES), the relationship between concentration and performance is not due to corporate collusion, but rather is the result of the company's efficiency $[7,8]$.

Companies that are more efficient can impose lower prices than its competitors, allowing them to get a larger share of the market [4]. More efficient companies can charge lower prices than their competitors and keep gaining economic profits, and the comparative advantage of being more Efficient allows them to obtain a larger share in the market, which leads to increased market concentration, and this concentration in the market benefits both companies and consumers: efficient companies can make higher profits while consumers benefit from lower prices [7,9].

Thus, if larger firms have a comparative advantage in production or services, these companies can achieve higher profits without resorting to collusive measures such as price increases or supply restrictions [5].

The assumption is there if a positive relationship between the company performance and its efficiency, whereas market concentration comes from competition, therefore companies with a low-cost structure will increase profits by reducing prices and expanding market share. The positive relationship between corporate profits and market structure attributed to the gains made by the most efficient companies through their market share, leading to increased market concentration. That is, the increased profits are supposed to return to the most efficient companies because of their efficiency and not because of coalition activities as SCP suggests [10].

Several studies were conducted on the financial and industrial sectors. These studies focused on the banking sector and the insurance sector, in general, did not get sufficient attention and the insurance sector in Jordan, in particular, has not conducted any studies related to this subject. In 1998, Bajtelsmit and Bouzouita [5] studied the market structure and performance of private vehicle insurance in the United States by aggregating data at 50 states for 1984-1992. The results showed a strong positive relationship between the level of concentration and profitability at the state level and supported the existence of the SCP hypothesis.

In 2005, Choi and Weiss [11] studied the relationship 
between the market structure and the performance of non-life insurance companies in the United States during 1992-1998 to test three hypotheses: the traditional SCP hypothesis, the Relative Market Power hypothesis, and Efficient Structure hypothesis. The results of the SCP hypothesis were supported by a statistically significant relationship between the efficiency of the company and its performance, which reflected positively on the profitability indicators and the performance of the company in general. It also found that high-profit companies are increasing their market share, and increasing its market concentration.

Jedlicka and Jumah [12] examined a sample of 52 insurance companies in the Austrian market during 2002 and 2003. Their findings showed that there was no causal relationship between the structure of the market and the performance of companies in a manner that did not support the structure hypothesis. Also, they found the life insurance market is competitive and mature market and the non-life insurance market is concentrated, but there are no signs of collusion between companies.

Cole et al. [13] examined the relationship between the market structure and the technical performance of the US health insurance sector during the period 2002-2010. The results showed that the number of insurance companies operating in that sector increased in the United States, which led to a decrease in the concentration during the study period. Also, they found that there is a positive relationship in the health insurance sector with technical profits in a way that supports the hypothesis of the market performance structure.

Alhassan et al. [14], used panel data for 14 life insurance companies and 22 non-life insurers to test the SCP hypothesis and ES were used to understand the impact of market structure And the efficiency of insurance companies operating in Ghana on corporate profits. The results supported the SCP hypothesis in both the life and non life insurance market. Kaonga [15] also studied the relationship between the market structure and performance of the insurance companies in Zambia during the period 2005-2013. They found that the SCP hypothesis in the insurance market in Zambia did not hold and the ES hypothesis is more likely to apply.

\section{Data and Methodology}

\subsection{Data}

The study used panel data for 22 insurance companies operating in Jordan during the period (2000-2016). Two companies excluded from the study due to unavailability of data covering the entire study period. The data collected from the annual financial statements of the insurance companies.

\subsection{The Dependent Variable}

ROI: Return on assets of the insurer (i) in time ( $t$ ), many empirical studies indicated that the performance of the firm is analyzed using profitability and measured as the rate of return on assets [14]. To Analysis the performance of the insurer, we will use the return on assets, which measured by the insurer's net profit before tax dividing by the total assets of the insurer as at the end of the year, as follows:

$$
\text { Return on Assets }=\frac{\text { Profit Before } \text { Tax }}{\text { Total Assets }}
$$

\subsection{Independent Variables}

MS: Market share of the insurer (i) in time (t). This variable indicates the market power of each insurer to assess its impact on performance. Market share measured by the ratio of the premiums of each insurer to the total premiums in the market, in order to measure the extent to which these insurers dominate the economic activity in the insurance sector, as follows:

$$
\text { Market Share }=\frac{\text { Written Premium For Company }(x)}{\text { Total Written Premium in the Market }}
$$

Market structure of Jordan insurance sector during the period (2000-2016) determined by Herfindahl-Hirschman Index (HHI) and the concentration ratio (CR). We will use the market share to measure both these indexes.

The HHI index calculated through merging the relative size (market share) of all companies by dividing the market shares of all companies in the market and then aggregating them. The index ranges from 0 to 10,000 . The values that are less than 1,000 indicate a Low concentration, in the range from 1,000 to 1800 indicates a moderate concentration, the value of $\mathrm{HHI}$ above 1800 indicates a very high concentration, whereas the index value equal to 10,000 indicates a full concentration [16]. This indicator calculated in the following form:

$$
H H I t=\sum_{k=1}^{n} M S^{2}
$$

Where:

HHI: Herfindahl-Hirschman Index in time t. The result is multiplied by $(10,000)$.

MS: the market share of the company $(\mathrm{K})$ and measured by dividing the company's premiums on the gross premiums of the insurance market.

$\mathrm{n}$ : number of insurance companies in the market.

The other index is the Concentration ratio of the largest companies in the market, which represents the total share of the largest companies in terms of the size of premiums relative to the total premiums of the insurance market. It measures the extent to which these insurers dominate the economic activity in the insurance sector. The concentration ratio of the largest five insurers in the market considers one of the best indicators used to measure insurance concentration [17]. The index calculated in the following form:

$$
C R=\sum_{k=1}^{5} M S
$$

This ratio ranges between 0 and 1 , it approaches 0 , if there are a large number of small insurance companies and it equal 1 if they're a single insurance company in the market [18].

Table 1 shows the results of the index (CR5) and (HHI) for the insurance market in Jordan during the period (20002016). The increase in the value of the indexes indicates a 
low level of competition in the insurance market in Jordan during the study period. In other words, the insurance market in Jordan is a highly concentrated market where a few insurers controls a large market share of premiums.

The competitive situation can be classified as an oligopoly, since the market is concentrated by a few dominant insurers that acquire most premiums because of their large size, diversification of its insurance portfolio, in addition to the geographical spread of these companies compared to other small companies which have a market share between $1 \%$ and $3 \%$ of the total premiums in the insurance market in Jordan.

Table 1. Result of CR5 and HHI for the insurance market in Jordan for the period 2000-2016.

\begin{tabular}{lll}
\hline Year / Index & HHI & CR5 \\
\hline 2000 & 559 & 0.41 \\
2001 & 543 & 0.40 \\
2002 & 499 & 0.37 \\
2003 & 487 & 0.36 \\
2004 & 490 & 0.35 \\
2005 & 502 & 0.36 \\
2006 & 507 & 0.36 \\
2007 & 503 & 0.37 \\
2008 & 507 & 0.38 \\
2009 & 529 & 0.39 \\
2010 & 538 & 0.40 \\
2011 & 587 & 0.41 \\
2012 & 639 & 0.43 \\
2013 & 682 & 0.45 \\
2014 & 697 & 0.45 \\
2015 & 732 & 0.47 \\
2016 & 749 & 0.48 \\
\hline
\end{tabular}

HHI: Herfindahl-Hirschman Index.

CR5: The concentration ratio of the largest five insurance companies in the market.

ES: Technical Efficiency for the insurer (i) in time ( $t$ ), it was estimated by using the DEA method with the variable return to Scale. DEA is the non-parametric approach that employs linear programming techniques to construct the efficient frontier that envelope all the mixes between inputs and outputs of firms in the sample. Relative efficiency is estimated by comparing a set of inputs and outputs, and efficiency score between 0 and 1 one are given. The closer the value is to the one, the higher the efficiency. The closer the value is to zero, the lower the efficiency.

$$
0 \leq T E^{V R S} \leq 1
$$

To illustrate the model mathematically, suppose that $[X]_{i . j}$ is the input matrix, $[Y]_{r . j}$ is the output matrix, $\lambda$ is the vector of the variables weights, $Z$ is scale constraint, $\theta$ represents the technical efficiency of the Decision Making Units (DMUs) I, and $0 \leq \theta \leq 1$. The mathematical solution is [19]:

$$
\operatorname{Min}_{\theta, \lambda} \theta
$$

Subject to:

$$
\begin{gathered}
-Y_{j}+Y \lambda \geq 0 \\
\theta X_{j}-X \lambda \geq 0 \\
Z^{\prime} \lambda=0 \\
\lambda \geq 0
\end{gathered}
$$

DEA results are sensitive to the variables that used (inputs and outputs). The choice of method and variables have an important impact on the measurement and analysis of efficiency. As [14, 20, 21] the following variables used in efficiency measurement by DEA:

Inputs: total operating expenses, Debt and Owner's equity, and total technical Provisions.

Outputs: Net Earned premiums and investments Income.

Rein: Reinsurance of the insurer (i) in time (t). Reinsurance is a way of transferring the risk from the insurer to the reinsurer, in order to protect the insurer from unexpected financial losses that may be exposed to it. This reduces the insurer's retention of the premium that collects as it transferred to the reinsurance company in exchange for agreeing to cover the risks to which the insurer may be exposed. This variable is measured by dividing the total amount transferred to the reinsurers to the total premiums written by the insurer, as follows:

$$
\text { Reinsurance }=\frac{\text { Preimum } \text { Transfered to reinsurance Company }}{\text { Total Written Premium by Insurance Company }}
$$

Lev: leverage of the insurer (i) in time $(\mathrm{t})$. Leverage measured by the insurer's liability to its total Owner's Equity. The quality of investments assumed determines its impact on performance. Thus, the relationship between Leverage and performance becomes positive through sound investment options, which generates returns above expected losses, and bad investment decisions lead to a negative relationship with performance. As follows:

$$
\text { Levarage }=\frac{\text { Total liabilities }}{\text { Owner's Equity }}
$$

Risk: Underwriting Risk for the insurer (i) in time (t). Represent the risks facing the insurer in order to assess the efficiency of the insurance underwriting policy of the insurer and its impact on performance. This measure captures the uncertainty that the written premiums may not be sufficient to cover the losses incurred as a result of the insurer's underwriting policies. It is expected that there a negative relationship between underwriting risk and profitability, as the higher the insurer's risk, the lower its profitability. Underwriting risk measured by net cost paid claims to net income from premiums ratio, as follows:

$$
\text { Risk }=\frac{\text { Net cost paid Claims }}{\text { Net Earned Preimum }}
$$

\subsection{Empirical Model}

In order to estimate the impact of market share, technical efficiency, reinsurance, leverage, and underwriting risk, the study use the following model $[13,14]$ : 


$$
R O A_{i t}=\alpha+\beta_{1} M S_{i t}+\beta_{2} E S_{i t}+\beta_{3} \operatorname{Rein}_{i t}+\beta_{4} \operatorname{Lev}_{i t}+\beta_{5} \operatorname{Risk}_{i t}+\varepsilon_{i}
$$

Where:

$\alpha$ : represents the constant, i: insurance company, t: time period (in years), ROA: rate of return on assets, Rein: reinsurance ratio, Lev: leverage ratio, Risk: Underwriting Risk, , $(\beta$ 's) : Model parameters, and $(\varepsilon)$ : the random error.

\section{Data Analysis}

\subsection{Descriptive Analysis of Variables}

The summary statistics of the explanatory variables presented in the Table 2. One of the most important conclusions from this table is the large difference in market share between the companies; in addition, there are significant differences in technical Efficiencies between companies during the study period.

Table 2. Descriptive statistics for independent variables.

\begin{tabular}{|c|c|c|c|c|c|}
\hline Variable & MS & ES & Rein & lev & Risk \\
\hline Mean & 0.04 & 0.90 & 0.33 & 1.58 & 0.80 \\
\hline Median & 0.03 & 1.00 & 0.31 & 1.29 & 0.77 \\
\hline Maximum & 0.19 & 1.00 & 0.68 & 6.79 & 1.99 \\
\hline Minimum & 0.01 & 0.35 & 0.02 & 0.06 & 0.44 \\
\hline Std. Dev & 0.03 & 0.14 & 0.16 & 1.09 & 0.15 \\
\hline Observations & 374 & 374 & 374 & 374 & 374 \\
\hline
\end{tabular}

MS: market share. ES: Technical Efficiency scores. Rein: Reinsurance ratio.

Lev: leverage ratio Risk: Underwriting Risk

\subsection{Stationary Test}

To ensure that the study variables are stationary and that there is no Unit Root, the Levin-Lin-Chu Test (LLC) will apply. Table 3 shows the results of the LLC test, It shows that all the variables are stationary on the level, And (OLS) method can be applied [22].

Table 3. Stationary Test.

\begin{tabular}{llll}
\hline Variable & Value on Level without Trend & Probability & Result \\
\hline ROA & -3.45433 & 0.0003 & $\mathrm{I}(0)$ \\
MS & -3.12125 & 0.0009 & $\mathrm{I}(0)$ \\
ES & -9.881 & 0.0000 & $\mathrm{I}(0)$ \\
Rein & -3.30792 & 0.0005 & $\mathrm{I}(0)$ \\
Lev & -1.3582 & 0.0872 & $\mathrm{I}(0)$ \\
Risk & -3.85224 & 0.0001 & $\mathrm{I}(0)$ \\
\hline
\end{tabular}

ROA: rate of return on assets MS: market share. ES: Technical Efficiency scores. Rein: Reinsurance ratio. Lev: leverage ratio Risk: Underwriting Risk

\subsection{Multicollinearity Test}

To ensure that there is no multicollinearity, we analyzed the correlation coefficients $(\rho)$ between the explanatory variables using Correlation Analysis. If the correlation between the variables is weak, this indicates that there is no multicollinearity problem. The correlation coefficient in the Table 4 indicates that there is a week correlation between the explanatory variables.

Table 4. Correlation Matrix.

\begin{tabular}{llllll}
\hline Variable & MS & ES & Rein & Lev \\
\hline MS & 1 & & & \\
ES & -0.046841 & 1 & 1 & \\
Rein & 0.418379 & -0.226618 & -0.447613 & 1 \\
Lev & 0.046753 & 0.1303 & 0.0222 & 0.121481 \\
Risk & -0.163057 & 0.091414 & 1 & 1 \\
\hline
\end{tabular}

MS: market share. ES: Technical Efficiency scores. Rein: Reinsurance ratio.

Lev: leverage ratio Risk: Underwriting Risk

\subsection{Estimating the Model}

The table in the Appendix shows the statistical results of the two models of fixed and random effects. The explanatory power of both models is different as the coefficient of determination $R^{2}$ was (54\%) for the fixed effects model and $(43 \%)$ for the random effects model. Whereas the value of the adjusted $R^{2}(51 \%)$ was for the fixed effects model and 
$(42 \%)$ for the random effects model. The F statistics for both models were statistically significant. Durbin Watson was (1.90) and (1.71) for the fixed effects and the random effects model respectively.

To determine which model, the fixed effects model and the random effects model are more appropriate in explaining the ROA variations, the Hausman test was used, and the more precise model is determined and selected. If the null hypothesis is accepted, the random effects model is used. Otherwise, the fixed effects model is used. As follows:

$H_{0}$ : The random-effects model is preferable to the fixed effects model, Therefor; the generalized least square (GLS) method is used.

$H_{1}$ : The fixed-effects Model is preferable to the random effects model Therefor; the ordinary least square (OLS) method is used.

In the Hausman's test result, the value of chi-seq. Calculated less than the tabulated value and not statistically significant and therefore we cannot reject the null hypothesis and therefore the model of Random effect is preferred on the fixed effect model.

The results of the Random Effect GLS model were as follows:

$$
R O A=0.373+0.605 M S+0.050 \text { ES - 0.098 Rein - 0.019 Lev - 0.448 Risk }
$$

T-state: [6.998] [3.433] [1.225] [-1.990] [-2.906] [-7.935].

Table 5. Statistical result

\begin{tabular}{llll}
\hline Observation & 374 & F-statistic & 56.549 \\
$R^{2}$ & 0.434 & P-Value & 0.000 \\
Adjusted $R^{2}$ & 0.427 & D-W & 1.715 \\
\hline
\end{tabular}

The results show a statistically significant positive relationship between the market share of each insurer and its return on assets, which mean that as the insurer increased and acquired a larger market share it will increase its competitive advantage, which increases its return on assets. Thus, the result supports the traditional (SCP) hypothesis. This finding confirmed the findings of (Cole et al., 2015; Alhassan et al., 2015, and Koanga, 2015) [13-15].

In contrast, the effect of Technical efficiency on ROA is weak and insignificant, indicating that there is no relationship between the efficiency of the insurer and its performance. In a manner, that rejects the efficient structure hypothesis (ES) in the insurance market in Jordan.

This can be explained by the fact that insurer efficiency doesn't take into account the quality of output from the input used where the higher proportion of the insurance portfolio, refer to the compulsory motor insurance, which is unlibrized and its tariffs determined by the regulator.

Insurer leverage has a negative effect on return on assets, This can be explained by the fact that the company's reliance on debt to finance its activities is not feasible and has a high cost to the insurer, which negatively affects its profits. This confirms findings of Malik (2011) [13] and Ahmad et al. (2011) [24], in contrast to the findings of (Akotey et al., 2013) [25].

Reinsurance has a negative effect on return on assets. As any increase in the reinsurance ratio will lead to a lower rate of return on assets. This is because the transfer of premiums to reinsurers abroad may cause the insurer's profits to fall if the value of compensation and claims paid less than the value of premiums transferred to the reinsurance, and insurer's loss profits that could have been achieved in the case of the insurer have a higher retention of premiums.

Also underwriting risk have a negative effect on the return on assets, The insurer evaluates and pricing each policy separately in proportion to the amount of compensation expected in the event of a risk, and the right pricing policies lead to a decrease in this ratio (known as loss ratio), which reflects positively on the profitability and performance of the insurer, and vice versa If the wrong pricing policies are applied, the rate of return on assets is decreased. This inverse relationship was predicted and consistent with the study of (Alhassan et al., 2015; Akotey et al., 2013) [14, 25].

In Table 5 , the $\left(R^{2}\right)$ refers to the ability of explanatory variables to interpret differences in the dependent variable. Given this value of $(43 \%)$, the estimated model can explain $(43 \%)$ of the difference in the ratio of return on assets between insurers. This ratio considered good and acceptable in panel data. The value of $F$ statistics reflects the significance of the regression model used in the study, and given the P-value of the F test, it can be concluded that the model is good and statistically significant. Finally, the value of the D.W test indicates that there is no autocorrelation problem in the model used. Where its statistic was between the highest value and the lowest value, since $\left(d_{U}=\right.$ $\left.1.725>d=1.715>d_{L}=1.623\right)$.

\section{Conclusions and Recommendations}

The study investigates the impact of Structure-Conductperformance (SCP) and efficient structure (ES) hypothesis, as well as Reinsurance, leverage, and Underwriting Risk, on the performance of insurers in Jordan measured by Return on Assets. This study used the Panel data from (22) insurance companies operating in Jordan during the period (2000-2016).

The study found that the insurance market in Jordan is highly concentrated, where a few companies control a large market share of premiums, thus the competitive situation in the market can be classified as an Oligopoly.

The result supported that the (SCP) hypothesis applied in the insurance market in Jordan indicating that there is a positive relationship between market share and ROA, but Reinsurance, leverage, and Underwriting Risk have a negative relationship with ROA, while Technical Efficiency has a weak impact on the performance of insurers in Jordan, in a way that not support the (ES) hypothesis in the insurance market in Jordan. 
Based on the result, the study recommends that insurers should work to increase their market share throw merger with each other, which will positively affect the performance of those insurers; especially that the Jordanian government encourages such mergers through incentives to insurers resulting from mergers such as tax holidays and exemptions from other government fees. Also, insurers should work on the proper selection and pricing of their Policies according to actuarial studies to mitigate the risk (loss ratio) of its business, and the Government should take actions to Liberalize Motor compulsory insurance and give insurers the freedom to underwrite and risk pricing.

\section{Appendix}

Table A1. Statistical Result of estimated econometric model.

\begin{tabular}{lll}
\hline Variable & Fixed Effect & Random Effect \\
\hline MS & 0.555003 & 0.605234 \\
t-Statistic & {$[2.073525]$} & {$[3.433985]$} \\
P-value & $(0.0389)$ & $(0.0007)$ \\
ES & 0.054622 & 0.050082 \\
t-Statistic & {$[1.636626]$} & {$[1.225137]$} \\
P-value & $(0.1026)$ & $(0.221)$ \\
Rein & -0.165052 & -0.098341 \\
t-Statistic & {$[-3.3504]$} & {$[-1.990405]$} \\
P-value & $(0.0009)$ & $(0.0473)$ \\
Lev & -0.015243 & -0.019497 \\
t-Statistic & {$[-3.03258]$} & {$[-2.905606]$} \\
P-value & $(0.0026)$ & $(0.0039)$ \\
Risk & -0.475233 & -0.44824 \\
t-Statistic & {$[-14.22574]$} & {$[-7.934789]$} \\
P-value & $(0.0000)$ & $0.0000)$ \\
Constant & 0.408458 & 0.373973 \\
t-Statistic & {$[9.467382]$} & {$[6.998834]$} \\
P-value & $(0.0000)$ & $(0.0000)$ \\
Observation & 374 & 374 \\
$R^{2}$ & 0.545357 & 0.434493 \\
Adjusted $R^{2}$ & 0.511291 & 0.426809 \\
F-statistic & 16.00907 & 56.5487 \\
$P$-Value & 0.0000 & 0.0000 \\
D-W & 1.90458 & 1.715845 \\
\hline & & $R$ \\
\hline
\end{tabular}

MS: market share. ES: Technical Efficiency scores. Rein: Reinsurance ratio. Lev: leverage ratio Risk: Underwriting Risk

\section{References}

[1] Bain، J. S., (1951), Relation of Profit Rate to Industry Concentration: American Manufacturing, 1936-1940. The Quarterly journal of Economics, 65 (3), 293-324.

[2] Jaloudi, M. (2018), Determinants of the Efficiency of Insurance Companies in Jordan. Unpublished $\mathrm{PhD}$ Dissertation, University of Jordan.

[3] Mason, E. (1939). Price and Production Policies of LargeScale Enterprise. American Economic Review, 29(1), 61-74.

[4] Stozle, T. r, Weiss, M, and Wende, S. (2011). Market Structure, Efficiency, and Performance in the European
Property-Liability Insurance Industry.

[5] Bajtelmit, V. L. and Bouzouita, R. (1998), Market Structure and Performance in Private Passenger Automobile Insurance. Journal of Risk and Insurance. 65(3), 503-514.

[6] Shaik, S., Allen, A., Edwards, S., and Harris, J. (2009), Market Structure Conduct Performance Hypothesis Revisited using Stochastic Frontier Efficiency Analysis. Agribusiness \& Applied Economics.

[7] Demsetz, H., (1973), Industry Structure, Market Rivalry, and Public Policy, Journal of Law and Economics, 16: 1-9.

[8] Smirlock, M. (1985). Evidence on the (Non) Relationship Between Concentration and Profitability in Banking. Journal of Money, Credit and Banking. 17(1), 69-83.

[9] Peltzman, S., (1977), The Gains and Losses From Industrial Concentration, Journal of Law and Economics, 20: 229-263.

[10] Molyneux, P., and Forbes, W. (1995). Market Structure and Performance in European Banking. Journal of Applied Economics, 27, 155-59.

[11] Choi, B. P. and Weiss,M. A. (2005), An Empirical investigation of Market Structure, Efficiency and Performance in Property- Liability Insurance. Journal Of Risk and Insurance. 72 (4), 635-673.

[12] Jadlicka, L. and Jumah, A. (2006), The Austrian Insurance Industry: A Structure, Conduct and Performance Analysis, Institute for Advanced Studies. Economic Series Working Paper.

[13] Cole, C.R. He, E. and Karl, J.B. (2015), Market Structure and the Profitability of the U.S. Health Insurance Marketplace: A State Level Analysis. Journal of Insurance Regulation. 34 (4).

[14] Alhassan, A. Adidsson, k. j. and Asamoah, M. F. (2015), Market Structure, Efficiency and Profitability of Insurance companies in Ghana. International Journal of Emerging Markets, 10 (4), 648-669.

[15] Konga, k. (2015), Market structure, Conduct and Performance of Firms in the insurance Industry: Evidence from Zambia. Unpublished Master Dissertation, The University OF ZAMBIA.

[16] Lipezynski, J.; Wilson, J. and Goddard, J. (2005), Industrial Organization: Competition, Strategy, and Policy. (2nd) Prentice Hall: England.

[17] Scherer, F. M. and Ross D. (1990), Industrial market structure and economic performance, (3ed). Houghton-Mifflin: Boston.

[18] Parida, T. K. (2017), Measuring Competition in Indian NonLife Insurance Industy: Some Evidence in the Post-Reform period. Bimaquest, 17 (1), 60-78.

[19] Ramanathan, R. (2003). An Introduction to Data Envelopment Analysis: A Tool For Performance Measurement. New Delhi: Sage Publications Ltd.

[20] Diacon, S. (2001), The Efficiency of UK General Insurance Companies. Center for Risk \& Insurance Studies, CRIS Discussion Paper Series, 2001III.

[21] Yang, Z. (2006). A two-stage DEA model to evaluate the overall performance of Canadian life and health insurance companies and computer. Mathematical and Computer Modelling. 43 (7-8), 910-919. 
[22] Baltagi, B. H. (2005), Econometric Analysis of Panel Data. 3rd Edition, John Wiley \& Sons Inc., New York.

[23] Malik, H. (2011), Determinants of insurance companies profitability: an analysis of insurance sector of Pakistan, Academic Research International, 1 (3), 315-321.

[24] Ahmed, N., Ahmed, Z. and Usman, A. (2011), Determinants of performance: a case of life insurance sector of Pakistan, International Research Journal of Finance and Economics, 61, 123-128.

[25] Akotey, J. O., Sackey, F. G., Amoah, L. and Manso, R.F. (2013), "The financial performance of life insurance companies in Ghana", The Journal Risk Finance, 14( 3), 286302 . 